\title{
Reactivity in the rat: Ovariectomy fails to affect open-field behaviors*
}

\author{
PAUL M. BRONSTEIN $\dagger$ and STEPHEN M. HIRSCH \\ Brooklyn College of the City University of New York, Brooklyn, New York 11210
}

\begin{abstract}
The behaviors of ovariectomized and control female rats were sampled during repeated open-field trials. In none of these investigations did surgery have any significant effect. These failures were interpreted as limiting current views of altered stimulus reactivity resulting from this surgical insult. These data suggest also that age-related changes in open-field activity are not manifestations of the altered gonadal secretions correlated with the onset of puberty.
\end{abstract}

The behavioral effects of ovariectomy in rats are, of course, multiple. Among these are reductions in wheel-running activity (e.g., Richter \& Uhlenheuth, 1954), and lowered sensitivities to both footshock and quinine (Marks \& Hobbs, 1972). Marks and his associates have attempted to explain these effects as reductions in stimulus reactivity mediated by the body-weight increases resulting from the surgical insult. Footshock and quinine thresholds, for instance, are not altered in ovariectomized females if the increased adiposity following surgery is disallowed (Marks, Fargason, \& Hobbs, 1972). Furthermore, other treatments resulting in heavier animals are known to affect these behaviors in a manner similar to the ovariectomy. Age and sex are two such variables, with males less sensitive to footshock than the lighter females; similarly, older rats are less sensitive than juveniles (Paré, 1969).

The current studies attempt to extend this analysis to investigations of open-field behavior where age, sex, and the nutritional history of rats are known to alter activity in accord with the body-weight hypothesis. Older animals are less active than juveniles (Bronstein, 1972a; Furchtgott, Wechkin, \& Dees, 1961; Valle, 1971), males are less active than females (Levine \& Broadhurst, 1963; Masur, 1972), and rats made heavy by alterations in the food regimen are less active than leaner conspecifics. Frankova and Barnes (1968) noted, for instance, that the exploratory activity of malnourished rats was significantly greater than that of adequately fed and heavier conspecifics. Hence, these series of parallel results suggest that ovariectomized females may be less reactive to the novelty of the open field than intact controls.

Typically, the running wheel has been seen as far more sensitive to estrous-related changes than other

*This research was supported by Grant 10239 from the Research Foundation of the City University of New York and by Grant MH 22027-01 from the National Institute of Mental Health. We wish to thank F. Dmitri Wolk off for his technical assistance in the preparation of this paper. This paper is sponsored by Ralph R. Miller, who takes full editorial responsibility for its contents.

tRequests for reprints should be addressed to Paul $M$. Bronstein, Department of Psychology, Brooklyn College, Brooklyn, New York 11210. activity-measuring devices (Bolles, 1963; Finger, 1961, 1969), a finding which suggests that the effects of ovariectomy should little influence open-field behaviors. However, Bronstein (1972a) and Valle (1971) have shown that a procedure of repeated open-field testing is more sensitive to the age variable than a more limited number of trials. Wolkoff and Levine (1973) showed a similar relationship with regard to the sex of the animals tested: sex-related differences become more pronounced with a procedure of multiple open-field trials. Therefore, this modification of the open-field procedure (repeated tests) was employed in an attempt to maximize sensitivity to the surgery.

A further reason for undertaking these experiments is Bronstein's (1972b) suggestion that there exists among female rats, at least, a postweaning critical period during which exposure to some conjunction of apparatus placement and handling by $\mathrm{E}$ results in heightened open-field activity. It was added (Bronstein, 1972b) that termination of this period might coincide with the onset of fertility. The cyclic pattern of ovarian secretions is one of the most visible correlates of puberty, and these endocrine changes may mediate the age differences in open-field performance. Therefore, gonadectomies were accomplished both in adulthood and at the time of weaning in order to abolish and, in the latter case, presumably to prevent ovarian cyclicity.

\section{METHOD}

\section{Subjects}

The Ss of Experiment I were 14 female albino rats of Sprague-Dawley descent purchased from Perfection Breeders (Douglassville, $\mathrm{Pa}$.) at approximately 100 days of age. After 5 days in the laboratory, half of the rats were bilaterally ovariactomized (anesthesia: ether) while the others served as sham-operated controls. Behavioral testing was initiated 3 weeks after surgery.

In Experiments II and III, the Ss were of the same stock and sex as in the first study, but were taken from litters born in the Brooklyn College vivarium. For the second investigation, $18 \mathrm{Ss}$ ( 9 OVEX and 9 SHAMs) were used, and surgery was performed at weaning when the Ss were 27-28 days old (anesthesia: Equi-Thesin-2.2 cc/kg). Again, Ss were run 3 weeks after surgery. 
The 5 OVEX and 6 SHAM Ss of Experiment III were weaned and surgically treated when '? days of age under Equi-Thesin anesthesia and open-field testing was initiated when the Ss were 91 days old.

All Ss were individually housed in standard cages with ad lib water and Purina Lab Chow. In Experiment I, the colony was always brightly illuminated, while in the final two studies the lights were switched on between 8 a.m. and 2 a.m. daily. Also, Ss were gentled (i.e., head-to-tail stroking at approximately 50 strokes/min) for the 7 days prior to testing in Experiment I. The same handling procedure was applied on alternate days in the last two experiments; this was begun when the Ss were 31 days old and continued until the start of testing. The effects of surgery were always confirmed with vaginal smears or laparotomies following the behavioral tests.

\section{Apparatus and Procedure}

An open field $60-\mathrm{cm}$ square with walls $60 \mathrm{~cm}$ high was used in Experiment I. The apparatus was made of plywood and painted flat black except for the $1 / 2-\mathrm{cm}$ white lines that divided the floor into $1615-\mathrm{cm}$ squares. The field was dimly lit by a $40-\mathrm{W}$ incandescent showcase bulb, suspended vertically $3 \mathrm{~m}$ above the center of the open field, and wrapped with aluminum foil on all surfaces except the rounded tip of the bulb.

Each trial was begun by hand-carrying an $S$ from its home cage and placing it in the corner of the field, facing into that corner. The number of squares traversed was recorded manually on separate electromagnetic counters for each minute in the apparatus. A square was judged to have been crossed when the head and at least one forepaw of an S moved across one of the lines drawn on the floor of the chamber. At the conclusion of each 5-min trial, Ss were returned to their respective home cages and any excreta recorded and cleared from the apparatus before the next trial was begun. Testing was always undertaken in the early afternoon, and Ss received one trial on each of 2 consecutive days followed after 48 h by 6 additional consecutive days of testing.

For Experiments II and III a clear Plexiglas open field, $60.96 \mathrm{~cm}$ high and wide and $59.69 \mathrm{~cm}$ deep, was used. The apparatus was placed within a sound-insulated outer shell $(91.44 \mathrm{~cm}$ high and measuring $73.66 \mathrm{~cm}$ on a side), which was fitted with a blower to mask external noises and open on one side rendering the open field accessible to observation. Individual Ss were placed into the apparatus through a $12.07 \times 12.70 \mathrm{~cm}$ door in a corner of the front wall of the field. The tan Plexiglas floor of this open field was quartered by two $1 / 4-\mathrm{cm}$-wide, perpendicular black lines intersecting at the floor's center, and a $1.12-\mathrm{W}$ bulb centered on the ceiling of the field illuminated the chamber. The upper portion of front wall of the open field could be swung outward, thus facilitating the removal of the rats following an observation period.

After hand-carrying and placing an animal into the apparatus, E manually operated a console of pushbuttons used to record the number of squares crossed, duration of quadrupedal movement (walking or running), and the number and duration of grooming and rearing movements. Rearing occurred when an animal's forepaws were lifted concurrently in any context other than for rubbing or scratching its body. These latter actions were considered grooming, a category also including any licking or biting of the body. The buttons were interfaced with counters registering each minute of activity separately; trial duration was $3 \mathrm{~min}$ in each of the final two studies. Latency to traverse the first square was also recorded. This was accomplished by manually starting a clock when the door to the field was closed behind an S; this timer was automatically shut down when the first square cross was registered. Latencies of less than $1 / 2 \mathrm{sec}$ could be reliably recorded in this manner, and this proved sufficiently sensitive to Ss' behavior. Finally, the floor of the apparatus was wiped with dilute acetic acid (2\%-3\%) following each trial. The Ss of Experiment II were run for 12 consecutive days, while 9 consecutive daily trials were employed in Experiment III.

\section{RESULTS}

In each study, two-way analyses of variance (the independent variables being surgical treatment and days of testing) were used to analyze the body-weight data, and, in Experiments II and III, square-cross latencies. A third variable, repeated minutes of testing, was used in analyzing the other measures (cf. Winer, 1962). Unless otherwise indicated, the criterion for statistical significance was $p<.05$. In every study, the OVEX females showed a weight gain which was significantly greater than that of the SHAMs. Also, the former group was always reliably heavier than the sham-operated Ss prior to open-field testing.

It should be noted that there was a complete absence of defecation in the open field in Experiments II and III; this was due, perhaps, to the extensive handling of the Ss prior to their running. The Ss of Experiment I did defecate during testing, but there were no significant differences in this measure as a function of surgery. The probability of an animal eliminating during a test was approximately 0.60 in each group.

There was no reliable effect of surgical treatment on square crossing in Experiment I; also, the variable of days failed to have any reliable impact on behavior. There was, however, a significant within-trial decrement in activity $(\mathrm{p}<.01)$, as well as a significant Surgery by Minute interaction. The habituation of the controls was significantly greater than that of the OVEX females. Further, there was a significant Days by Minute interaction $(p<.01)$, for which the significantly increasing rate of square crossing during Minute 1 was responsible. In no other minute was there any daily activity increment. The three-way interaction of surgery, days, and minutes was not significant $(\mathrm{F}<1.00)$.

The findings of Experiment II and III were similar to those of the first study in that no main effect of surgery was apparent in any index of behavior. There was a reliable decrement in latency to cross the first square over successive days of testing in both of these investigations. This change in latencies always was apparent in both groups, but in Experiment III, a significant Surgery by Days interaction $(p<.01)$ indicated a greater decrement among the SHAMs.

The last two studies differed from the first in that all groups showed significant day-to-day increments in square crossing (see Fig. 1). This significant daily increase was also apparent in ambulation and grooming durations, as well as on both indices of rearing in Experiment II. The rearing effects are documented in Fig. 2.

\section{DISCUSSION}

Taken together, these studies indicate that the consequences of gonadectomy little affect the open-field behaviors of female rats. Variations in the age of the Ss, both at the time of surgery and at the time of testing, did not significantly alter this null effect. Hence, it appears that the process(es) of stimulus reactivity, hypothesized as inversely proportional to a rat's body 


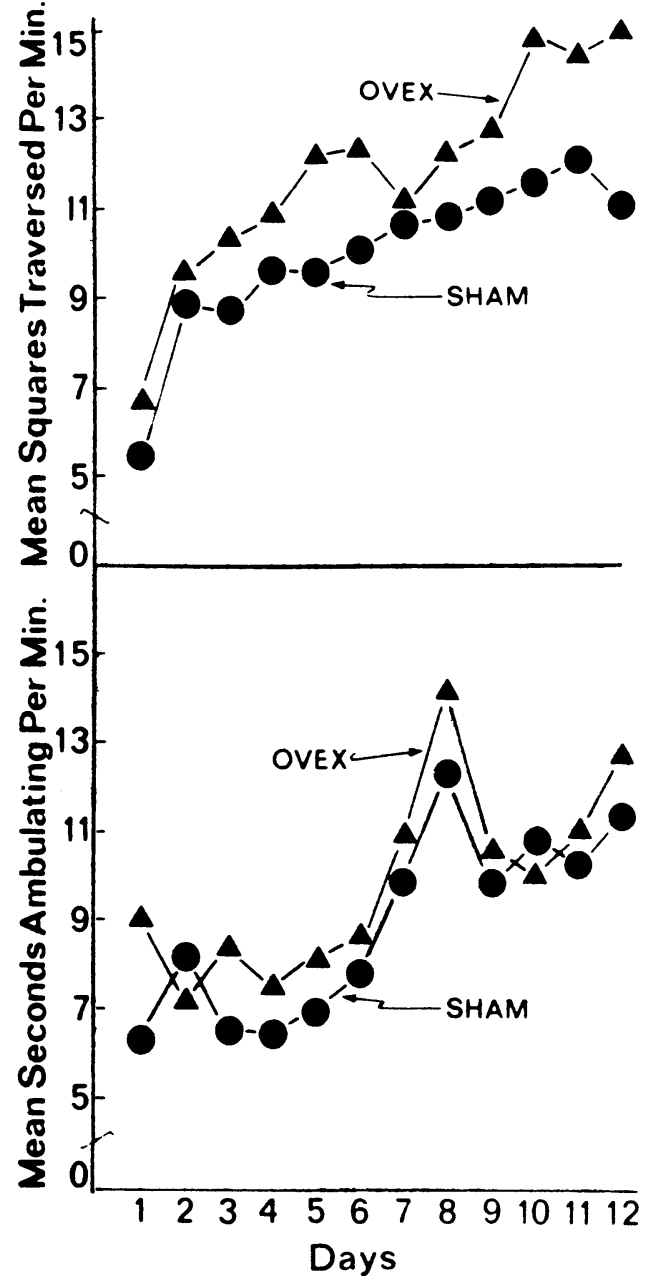

Fig. 1. Square crossing (upper panel) and duration of ambulation (lower panel) as a function of surgical treatment and days of testing during Experiment II.

weight by Marks and his colleagues (e.g., Marks \& Hobbs, 1972), can not as yet be generalized beyond ingestive and shock-related behaviors.

As a further test of the Marks et al proposition relating changes in body weight to responsiveness to stimulation, Spearman rank correlations were performed on the data from the final two studies (cf. Siegel, 1956). The attempt here was to determine which behavioral attributes, if any, correlated with the body weights of the animals, and three sets of correlations were undertaken: (a) Body weights on the first day of open-field testing were compared with all Day 1 behaviors. (b) The average weight for each animal (from weaning through the final day of open-field testing) was correlated with each index of activity (the totals for all testing days). (c) Finally, the weights of the Ss on the final day of open-field testing were compared with every activity measure, again using the sum of each S's activities for all test days.

Of these 42 correlations only one was significant. In Experiment III there was found a positive correlation between body weights and square latency on the first day of exposure to the open field $\left(r_{s}=0.536, \mathrm{~N}=11, \mathrm{p}<.05\right)$. While lighter Ss tended initially to be more reactive to the novel environment of the open field, the failure to find a similar relationship in Experiment II and the great preponderance of nonsignificant correlations suggest that within the limitations of the current investigations open-field behavior is unrelated to body weight.

The present results also argue against the hypothesis that the maturational changes reflected in female rats' open-field behaviors may result from an age-related change in the ovary and its secretions. Bronstein $(1972 \mathrm{a}, \mathrm{b})$ observed that an activity increment over repeated days of testing appeared to be a unique characteristic of immature females; even with 60 consecutive days of measurement, no day-to-day increment was apparent among adults. The final experiment of the current series is in contradiction to these earlier findings since 3-month-olds here showed a highly significant increase in ambulation over days. The procedural differences between the current experiments and the earlier work are numerous, but the amount and timing of the handling may be a crucial variable in accounting for this disparity across studies. A unique component of the experience of females in Experiments II and III, as well as in prior studies (Bronstein, 1972a, b, 1973), is that each of the groups displaying

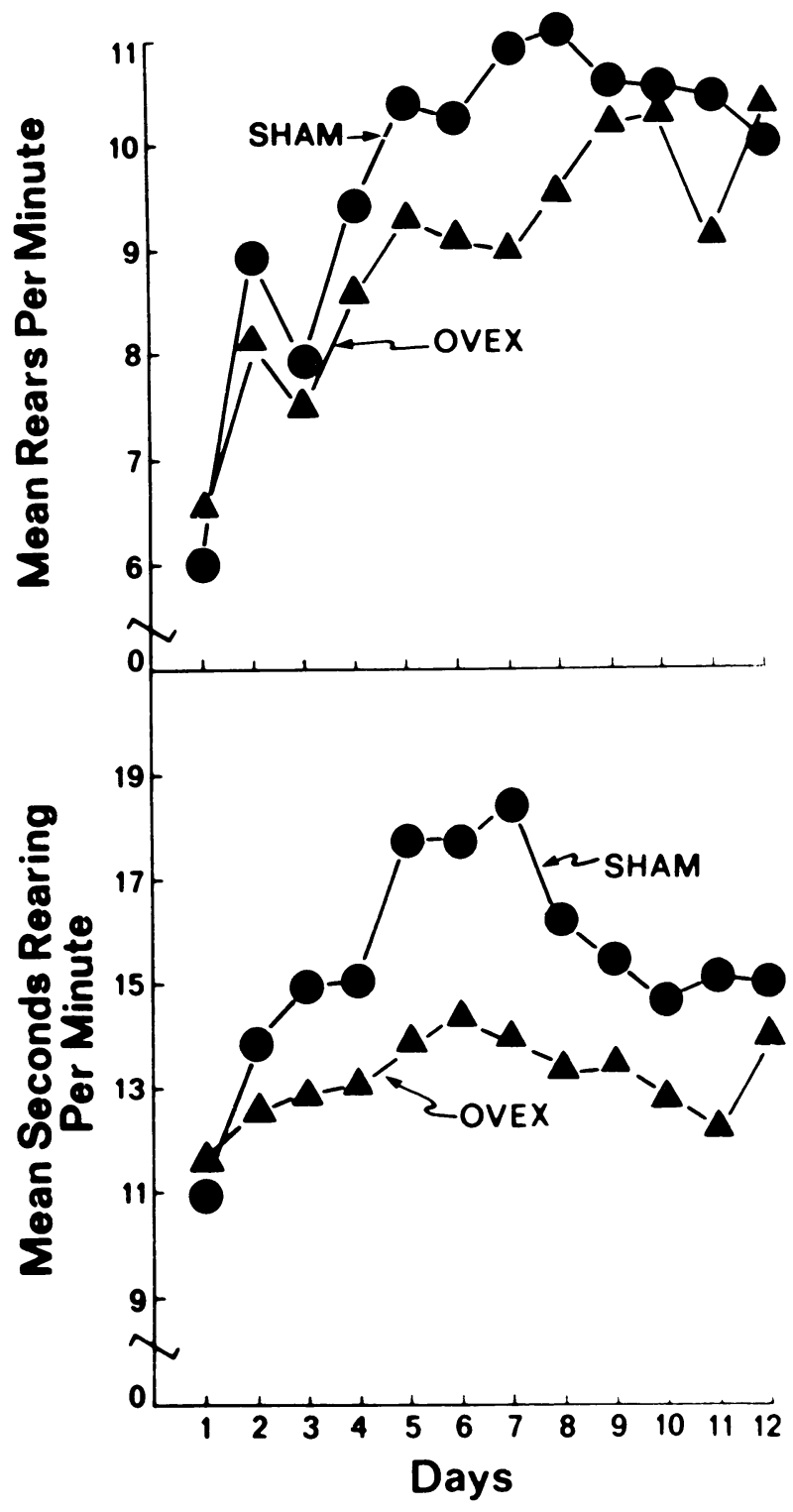

Fig. 2. Mean frequency and duration of rearing behavior in Experiment II as a function of surgical treatment and days of testing. 
an activity increment as a function of repeated trials had some gentling by an $\mathrm{E}$ prior to the 40th postnatal day. Those not exhibiting this day-to-day activity change also lack this experience as juveniles. Wolkoff and Levine (1973) showed that some postweaning handling is essential for obtaining an activity increase in female rats, and it appears also that extensive gentling in adults will not suffice to produce a pattern of increasing open-field activity (Bronstein, 1972b; Wolkoff \& Levine, 1973).

Hence, we hypothesize that female rats may be relatively sensitive to handling at about the time of weaning with gentling at this time being a prerequisite for heightened open-field activity, whether the apparatus exposure occurs shortly after weaning (Wolkoff \& Levine, 1973), or at some later age, as in the final experiment of the present paper.

Whatever the additional significance, if any, of gentling rats at the time of weaning, the current studies show that open-field activities in the female rat are not related to the presence of a functioning ovary. Similarly, the influence of handling in determining a daily increase in open-field locomotion appears also not to be influenced by an ovariectomy preceding the handling.

\section{REFERENCES}

Bolles, R. C. A failure to find evidence of the estrous cycle in the rat's activity level. Psychological Reports, 1963, 12, 530.

Bronstein, P. M. Repeated trials with the albino rat in the open field as a function of age and deprivation. Journal of Comparative \& Physiological Psychology, 1972a, 81, 84-93.

Bronstein, P. M. Open-field behavior in the rat as a function of age: Cross-sectional and longitudinal investigations. Journal of Comparative \& Phy siological Psychology, 197 2b, 80, 335-341.

Bronstein, P. M. R eplication report: Age and open-field activity of rats. Psychological Reports, 1973, 32, 403-406.

Finger, F. W. Estrous activity as a function of measuring device.
Journal of Comparative \& Physiological Psychology, 1961, 54, 524-526.

Finger, F. W. Estrous and general activity in the rat. Journal of Comparative \& Physiological Psychology, 1969, 68, 461-466.

Frankova, S., \& Barnes, R. H. Influence of malnutrition in early life on exploratory behavior in rats. Journal of Nutrition, $1968,96,477-484$.

Furchtgott, E., Wechkin, S., \& Dees, J. W. Open-field exploration as a function of age. Journal of Comparative \& Physiological Psychology, 1961, 54, 386-388.

Levine, S., \& Broadhurst, P. L. Genetic and ontogenetic determinants of adult behavior in the rat. Journal of Comparative \& Physiological Psychology, 1963, 56, 423-428.

Marks, H. E., Fargason, B. D., \& Hobbs, S. H. Reactivity to aversive stimuli as a function of alterations in body weight in normal and gonadectomized female rats. Physiology \& Behavior, 1972, 9, 539-544.

Marks, H. E., \& Hobbs, S. H. Changes in stimulus reactivity following gonadectomy in male and female rats of different ages. Physiology \& Behavior, 1972, 8, 1113-1119.

Masur, J. Sex differences in "emotionality" and behavior of rats in the open-field. Behavioral Biology, 1972, 7, 749-754.

Paré, W. P. Age, sex, and strain differences in the aversive threshold to grid shock in the rat. Journal of Comparative \& Physiological Psychology, 1969, 69, 214-218.

Richter, C. P., \& Uhlenheuth, E. H. Comparison of the effects of gonadectomy on spontaneous activity of wild and domesticated Norway rats. Endocrinology, 1954, 54, 311-322.

Siegel, S. Nonparametric statistics. New York: McGraw-Hill, 1956.

Valle, F. P. Rats' performance on repeated tests in the open field as a function of age. Psychonomic Science, 1971, 23, 333-335.

Winer, B. J. Statistical principles in experimental design. New York: McGraw-Hill, 1962.

Wolkoff, F. D., \& Levine, M. J. Post-weaning handling and repeated open-field trials with domesticated rats. Paper presented at the meeting of the Eastern Psychological Association, Washington, D.C., April 1973.

(Received for publication December 15, 1973.) 